\title{
EXPLORATORY STUDY ON AUDIENCE PERCEPTION OF INFORMATION CREDIBILITY ON MEDIA PLATFORMS IN GHANA
}

\author{
Philip Acquaye and Dr. Ibrahim Ofosu-Boateng \\ ${ }^{1}$ Lecturer, BlueCrest University College. Email: philacq@gmail.com \\ ${ }^{2}$ Lecturer/Dean of Students, Faculty of Business and Administration, West End University \\ College Amanfro, Ghana. Email ibraboat48@yahoo.com
}

Cite this article:

Acquaye P., Ofosu-Boateng I. (2021), Exploratory Study on Audience Perception of Information Credibility on Media Platforms in Ghana. British Journal of Mass Communication and Media Research 1(1), 16-27. DOI: 10.52589/BJMCMRTVLTYMLZ.

\section{Manuscript History}

Received: 14 Aug 2021

Accepted: 8 Sept 2021

Published: 14 Nov 2021

Copyright $\odot 2020$ The Author(s). This is an Open Access article distributed under the terms of Creative Commons Attribution-NonCommercialNoDerivatives 4.0 International (CC BY-NC-ND 4.0), which permits anyone to share, use, reproduce and redistribute in any medium, provided the original author and source are credited.
ABSTRACT: Using a focus group discussion, this study sought to understand how media audiences perceive information in the media environment in Ghana. The study found out that the prevalence of fake news on social media platforms serves as a disincentive to consumers of media messages from giving attention to information from some media platforms. Legacy media, radio and television, for many of the participants, present credible information on its platform with the belief that rigorous scrutiny is done by the media organisation before information is shared with their audiences on air. Though participants in the group discussions are often dismissive of media information they have doubts about, they occasionally, not routinely, verify information from news portals they deem credible. Participants also rely on their intuition to assess the truthfulness or otherwise of a story.

KEYWORDS: Fake News, Fact-Checking, Credibility, Focus Group 


\section{INTRODUCTION}

\section{Background of the Study}

The media in Ghana has had a checkered history and this in many ways affected the growth and sustainability of many media organizations and media outlets. Political influences on content creation, fewer media outlets, threats on the lives of journalists and imprisonment of journalists perceived to be opposed to the course of the government of the day were but a few of incidents that blotted the course that the media charted in the past.

The media environment in Ghana during the pre-independence era saw control of media in various forms - from management to content creation. Fewer news outlets were available, with the ruling class and governments majorly in control of its management and largely influencing content. Information in the media at the time was couched and shaped to re-echo political ideologies and to propagate government policies. (Sikanku, 2008).

Prior to the restoration of constitutional rule, however, media organizations and media outlets such as Daily Graphic, The Evening News, Ghanaian Times, Ghana Broadcasting Corporation and the Ghana News Agency were the main legacy media outlets owned and controlled by the state at the time. With the restoration of constitutional rule, coupled with factors such as deregulation of the broadcast media, divestiture of state-owned media organizations and the promotion of private investment, there emerged a sudden splurge in the number of privateowned newspapers and magazines and proliferation of privately-owned radio and television stations and services (Karikari, 1994).

The repeal of the criminal libel law at the time also provided a breather for many private businesses to invest in the establishment of media outlets. According to Acheampong (2017), Ghanaians witnessed a massive growth of the private media with a rapid expansion of the electronic media after the repeal of the criminal libel law. Acheampong observes that the repeal engendered an atmosphere of freedom of expression and this enabled the media to provide citizens with timely information. The now easily accessible information, courtesy of the media platforms, created an opportunity for citizens to exercise their right to free expression; an opportunity that enables media audiences to contribute to national debates and proffer suggestions towards the formulation of policies at the local and national level of stakeholder engagements.

As an information source for many, the media, over the years, has created an informed society thus weaponizing its audiences with information to be active participants in public discourse and decision-making processes. Media platforms, particularly the internet, have made access to information relatively easier and at a cheaper cost. Pollard \& Kavanagh (2019) observe that the internet has become the easy go-to media platform to access information and many countries including America fall on the internet for their daily news briefs. The increase in the use of the internet and its reliance is clearly argued out by the study but further notes that one's rating of reliability of information from any media platform is influenced by a number of factors including race, political affiliation and the echo chamber to which one belongs.

Lazer et al. (2017) argue that members in echo chambers, for instance, have the tendency to consent to the information that reinforces their beliefs and their ideological stands. According to Zimmer et al. (2019), echo chambers in social media refer to a relatively homogenous social space that reinforces or echoes beliefs and views within one's like-minded network while 
omitting or censoring opposing beliefs and views from other individuals or media sources. Arguably, the presence of echo chambers in online spaces is becoming a festering ground for fake news, and Lazer et al. (2017) opine that the tendency of people to follow like-minded people leads to the creation of echo chambers and filter bubbles, which exacerbate polarization.

Extant literature continues to raise doubts about the credibility of information from media sources as the splurge of fake news blurs the lines of credibility and reliability of media information. Often associated with online media, fake news has become a global buzzword (Farkas \& Schou, 2018) and its evolution and manifestation were closely linked with the rise of populist politics, digital capitalism, the transformation of the public sphere, and structural weaknesses of liberal and mainstream media (Mare, Mabweazara \& Moyo, 2019).

Though the concept of fake news is a relatively new phenomenon on online media, its existence predates legacy media (Luciano, 2016). According to Posetti \& Matthews (2018), the use of deceptive messages for mass communication is ancient, but never before has there been the technology to so effectively disseminate it. Their study recounts incidents of deceptive messaging from as far back as Circa 44 BC, during the Roman Empire, where crafted messages in the form of a propaganda campaign deployed Twitter-worthy slogans etched onto coins to smear the reputation of opponents.

In recent years, however, the epicentre often associated with narratives on fake news has been the 2016 presidential elections in the United States of America. America's President, Donald Trump's wielding of the term in a way to describe news that is unfavourable to himself as fake, is viewed by a satirical news organization, The Onion, as one of three distinct directions of fake news (Purcell, 2017).

Fake news is not new to the Ghanaian media. According to Ahiabenu, Ofosu-Peasah \& Sam (2018), fake news is endemic in the media environment in Ghana and it mostly manifests as fabricated content and false headline without connection to the content. The study further argues that as a growing part of the global news ecosystem, the prevalence of fake news has become commonplace to be associated with adverse impact on citizens' lack of trust not only in the news media but also in key governance institutions.

Ognyanova et al. (2020), in a study to assess the triggers in the rise and the overwhelming preponderance of fake news in media in America, observed that the lack of trust in mainstream media coupled with a rise in the trust of political institutions by those whose biases are aligned to the philosophy of a political organization has provided the grounds for fake news to flourish. The study further asserts that the extent to which fake news can undermine the public's confidence in mainstream media may not only leave its consumers misinformed but also make them more vulnerable when disaster strikes and may pose a threat to development.

Dominant literature makes the point that the prevalence of fake news in the media space continues to erode the trust of audiences in information coming from the media. According to Scheufelea \& Krausea (2018), often, media audiences and citizens, in general, are misinformed because they are unable to sift through and critically evaluate information in emerging (social) media environments.

Further, Scheufelea \& Krausea hold the view that lack of media literacy is one of the reasons why citizens become victims of misinformation in the media. Their study explains that other factors that create victims of media audiences include selective exposure on the part of the 
audiences, especially those trapped in echo chambers who are more likely to trust in information that reinforces their beliefs and will not give room for dissenting opinions.

Nielsen \& Graves (2017), in a study on audience perspective on fake news, note that the majority of the respondents are of the view that fake news has become more of a political buzzword used by politicians to criticize news media outlets. Invariably, scandalizing the media as a conduit for the propagation of fake news continues to fester and has created an image where media audiences are often at a loss about which media information is so credible enough for them to rely on. Nielsen \& Graves (2017) observe that there is a general scepticism about information from media sources and that this is generally affecting the reliability of such information. To believe whether information from the media is true or not, the study observes that consumers of media information rely on their own critical faculties to make sense of what they come across.

The media in Ghana, according to Ahiabenu, Ofosu-Peasah \& Sam (2018) is not sacrosanct in the milieu of fake news publications and this phenomenon makes audiences begin questioning the credibility of information from media sources (Pollard \& Kavanagh, 2019). This notwithstanding, media audiences also find themselves in a quagmire, often looking for alternative sources considered as more credible sources of information they could rely on.

To understand the phenomenon of fake news in the Ghanaian context, this study seeks audience perspective on how credible they perceive information in the media environment in Ghana and further interrogates to know measures participants take to authenticate the veracity or otherwise of information from the media.

\section{METHODOLOGY}

A focus group discussion is used in this research to understand the audience's perspective on information credibility in the media. The study also seeks to ascertain media outlets from which participants access information on issues of interest.

A publication by the American Statistical Association (1997) asserts that focus groups are an increasingly popular way to learn about opinions and attitudes. Their work affirms that focus group discussions give one a sense of what goes on with people's minds and lives that the average observer may not get with survey data.

Two focus groups (called Group one and Group two) were used in this study to gather information on participants' perception of information credibility in the media in Ghana. According to Masadeh (2012), there is no iron-clad rule about how many focus groups are enough. This study, thus, uses two different focus groups in order to get wide and diverse views on the audience's perspective of information credibility in the media. Participants between the ages of 18 and 35 constituted the first group while in group two, participants were those above the age of 35 years. The selection of participants within the age brackets was to ascertain patterns of perception across different age divides and also to find out whether the age bracket into which participants fall have any correlation with their preferred media type.

The two focus groups had seven participants each. According to Krueger (2002), a focus group with 6 to 10 is ideal but further notes that a range from 6-8 is preferred. Masadeh (2012) 
corroborates the position of Krueger and states that a focus group should have participants between 4 and 12. For this study, the selected number of participants to constitute the groups is consistent with the design of focus group composition as espoused in extant literature.

People selected as participants are persons who are active users of at least two media platforms for their daily news and other information of interest. The media outlets that participants actively access their information from include television, radio, newspaper, and online media.

The discussion was held on zoom, a virtual platform for synchronous meetings. The discussion was recorded for easy reference on comments and statements made by the participants. The study analysed statements and comments (Nili, Tate \& Johnstone, 2017) made by the participants in the group in response to questions posed by the facilitator.

As part of protocols for conducting the group discussion, participants remained anonymous in respect of references to comments made by them during group discussions but are only identified by labels, that is, Participant 1, Participant 2 etc. Together, the two groups had a total of 8 women and 6 men.

\section{FINDINGS AND DISCUSSION}

Participants in all two groups were of the opinion that the prevalence of fake news is a key contributing factor in choosing one media form over the other. Convenience was the other reason why some participants choose other media forms to source their information. A participant alludes to an instance where she read a news item on social media and later found out that the information shared on the social media platform was false after hearing other angles to the story on other media platforms.

"There was a day I read about a story on social media, and somehow became curious and wanted to check whether other media houses have carried the same story. Yes, they have covered it but the slant given to the story I read on social media was not closer to what I read on other platforms. It was so much sensationalized on social media that it was a departure from what the actual details of the story were", says Participant 6.

Another participant agrees that fake news has become a common phenomenon in online spaces but states that his choice of media is influenced by the nature of his daily schedule.

"Yes, fake news is true and real in the media today. But I come to work very early and leave quite late home. In my office, there is nothing like television nor a radio available for me to view or listen to. The online comes in handy and has become my primary reference point on a daily basis", says Participant 9.

The views of the participants confirm a generally held view that fake news is a common feature in the media environment today and that the media in Ghana is not an exception (Ahiabenu, Ofosu-Peasah \& Sam, 2018; Allcott, Gentzkow \& Yu, 2018; Lazer, 2017). 


\section{Information Credibility}

All the participants in the groups raised concerns about the credibility of information coming from the media.

"I'm careful about the information I consume as a media user. Often, my intuition tells me this story is too sweet to be true" (Participant 4).

Another participant (Participant 1) notes that "with my knowledge on how the media works, I look out for some key facts in the information such as the source of the information, to ascertain whether it is coming from a credible source or otherwise".

The scepticism expressed by the participants in trusting the media with information it publishes confirms the study by Nielsen \& Graves that the perceived lack of credibility of media information is eroding the trust of media audiences and spiralling the level of scepticism in media messages.

The heightening mistrust in media messages is, a result of experiences of participants who have read news items that turned out to be false and also heard comments from other media users who have been misled by a news item they read on a media platform. The experiences have created a phenomenon where audiences have become dismissive of information coming from media platforms they perceive to be inundated with fake news.

One of the participants (Participant 3) noted that media audiences appear to be in some form of dilemma not with the information from some media outlets, but from the barriers such media outlets pose.

"I decided to read a lot of newspapers knowing that they will not publish false information, especially the well-established media organisations in Ghana. But the cost involved in buying a newspaper every day was too expensive for me coupled with the fact that I have to walk some distance to get a newspaper at a newsstand. I have to fall back on social media and sometimes news portals because of the convenience of accessibility though I take information from the internet often with some doubts."

Though participants in the two groups unanimously mention social media as being in vogue, it is however perceived as having a lot of untrue and misleading content.

"Social media is a jungle where people dump any information they deem fit without any background verification", says Participant 1 . This assertion confirms the position of Shu et al (2016) that Social media enables the widespread of fake news, i.e., low-quality news with intentionally false information. 


\section{Media Preference}

Participants mentioned three media platforms they actively use and also source their information from - radio, television and online media. Ironically, missing in the list of media preferences is the newspaper.

\section{Online media}

According to a study by Quarshie \& Ami-Narh (2012) on the growth and use of the internet in Ghana, $45.6 \%$ of Ghanaians use the internet frequently for educational purposes, $33.75 \%$ frequently use it for news, and only $6.35 \%$ frequently use the internet for commerce. Amegatcher (2014) asserts that the majority of Ghanaians who use the internet are often on social media. According to the study, social media platforms are gradually replacing legacy media due to the ease with which one can access information. Participants in the group discussions have used, and continue to use online media to access information on varied interests. According to Participant 10, "it is the most convenient platform for me to get my information as compared to the rest".

Though the internet is the platform most used as a reference point in accessing information, it is the least trusted by the participants when it comes to the credibility of stories found in the medium. Participant 1 particularly points out social media as a breeding ground for fake news. "I'm often cautious about the information I read there, with experiences of reading false news on such platforms".

Though online media platforms emerge as the most used by participants in this study to access information, Participant 5 for instance shares the views of other members of the group and makes the point that he has confidence in selected online news portals but discounts information on social media as it is often polluted with misinformation. "I often visit some of the big media houses such as myjoyonline, peacefmonline and citi newsroom to read again, a story I have already read on social media to be sure of the truthfulness of the story"

\section{Radio}

Participants rate radio as one of the credible media platforms in the country and better in terms of the trustworthiness of information emanating from such platforms. "Radio produces very credible information in my view though this is not to say they are perfect. I believe that before information is sent out it goes through a lot of hands to cross-check all necessary facts before it is shared with the audiences'. says Participant 8.

A study by Adu (2003) about residents in the western part of Ghana on their perception of news credibility of two local FM stations in the region concluded that information emanating on the selected radio stations were highly rated as credible. The study confirms the position of some participants in this study who hold similar views that information on the radio has credibility and can be trusted. The inference in this study that alludes to the credibility of information on radio as a result of rigorous scrutiny stories go through is consistent with Adu's study that respondents cited objectivity, balance, and fairness as reasons for assigning high credibility rating to information on radio as a media platform. 
Radio was again acknowledged as a media platform that can be conveniently accessed on a mobile phone; hence it is often, for participants, an easier flip from online media (news portals and social media) to offline media on their phones (radio in this case).

'Radio as much as online media come in handy and even have the additional advantage of accessing information at no cost, ' says Participant 4.

The assertion that one can easily flip from online to offline on their phones to listen to radio was articulated by the first group of participants who are within the age bracket of 18-35 years. The second group of participants, (35 years and above) while agreeing that information on the radio has a high level of credibility, they get little time to listen to the radio.

"Because of my work schedule, I only get to listen to the radio only on my way to work while driving and a few times in my office" (Participant 8).

\section{Television}

Television is one medium mentioned by a participant in the group discussion as having credibility in terms of the information shared with its audiences on the platform. A report by the licensing authority in Ghana, the National Communication Authority (2017), indicates that there are 128 television stations licensed to operate in Ghana and of this number, 53 are operational while the remaining 75 are presently not on air. Television was not frequently viewed, as observed by one participant (Participant 3 ) because it is quite expensive to own one. In addition, the issue of its portability makes television a difficult option for accessing information.

According to the Ghana Media Measurement Report (2020), as cited by Koney (2020), TV3, United Television and Adom TV have the highest audience share across the country. It was noted in the discussion that participants who watched television as one of the platforms where they accessed information often referred to TV3 or United Television as television networks they watch for their news and other information of interest. The reference to these television networks with the highest number of viewership reinforces their dominance in the television media spectrum in Ghana. Participant's affirmation that the credibility of information from such sources as TV3 and United Television is a reflection of the level of trust in information coming from such media platforms.

\section{Information Authentication}

The findings from the focus group discussion show that the majority of the participants have not developed any means by which they ascertain the veracity of the information they come across in the media nor do they rely on any fact-checking website organisation to verify the truth or the falsity of media information. In instances where a person is doubtful of information, he dismisses it outrightly without any rigorous fact-check or reference to a third party for assistance to ascertain the truthfulness or otherwise of a story. "I'm aware of fake news particularly on social media but I have no knowledge of any organization that is into factchecking and I either read from reputable online news portals to verify the story or I don't believe it", says Participant 10. 
A member of the group who asserted that he occasionally tries to verify information from the media, though not as a routine, says 'it is often the case that I fall on other news portals such as Citinewsroom or myjoyonline to ascertain the veracity of a news story I read on social media. If these news portals have not reported on them, I consider them as fake news" (Participant 3).

Authenticating news or information on a media platform is done based on one's intuition. So for the members in the group discussion, if they have doubt about a story, they dismiss it as false, giving no credence to it at all.

This insight shared by the group members reinforces the position by Scheufelea \& Krausea (2018) that media audiences usually rely on their own critical thinking to sift information to determine whether to accept a story as true or false. Their study argues that media audiences eventually adopt a dismissive approach to media messages they are not sure of. This development, as noted, in their study, can be detrimental to human and societal development where important information may be discounted because a media consumer has doubts over its credibility.

Participant's reference to online news portals as a means of verification is a reflection of trust in some selected online media platforms though the general view of the online space being inundated with fake news continues to cast doubt over the credibility of information on online platforms. This phenomenon of cross-checking information from one media platform on another media platform goes to indicate how the internet serves as its own check and balances. The absence of the practice where information in doubt from the media is not verified from an identifiable fact-checking website puts media consumers in a position where they are either dismissive of information they doubt or open themselves up to be served with a myriad of information of which some may be fake news.

\section{Age and Media Preference}

The study constituted two different focus groups with 7 participants each. Group one which had participants with the age bracket of 18-35 are mostly students of tertiary institutions. The use of online platforms to access information is a regular practice. Participants from age 36 and above constituted Group Two and like Group One, online media is their easy go-to place to access information. All members in Group two are in the working class and their preference of online over other forms is the convenience of access it offers though members of this group are often sceptical of the credibility of information emanating from social media.

The use of online media to access information is a common practice by all participants across the age brackets in this study. However, participants in Group Two, most in the working class, are motivated by the convenience the internet offers them to source their information. Although the preference for legacy media is key, daily work schedules are a barrier to access information on their preferred media platform. Participant 10 notes for instance that "I like TV because of the pictures that accompany the story read on screen. It assures me of truth in the story". Group one is motivated to use more online sources irrespective of the risk of exposure to fake news simply because of ease of access. "It is less expensive and very easy to access a lot of information fast”, notes Participant 1. 


\section{CONCLUSION}

It is evident from the study that the phenomenon of fake news is widespread on all media platforms in Ghana. This has largely affected the level of trust media audiences have in information coming from the media, especially online media.

Fact-checking is an activity that is casually undertaken by the participants even though organisations and websites exist in the country to assist media consumers to authenticate the information from the media they have doubts about.

The evaluation of legacy media (radio and television) as a platform that shares credible information on the basis that they undertake rigorous checks before sharing information with the general public points to a reliance on third parties to do a thorough check before putting out messages on a media platform for public consumption.

Though the internet is noted to be a convenient means to access information on mobile phones especially, because of the multi-mediality of mobile phones, where legacy media like radio can also be accessed on them, it becomes an easy 'weapon' for media audiences to analyse, evaluate, and make an informed judgment on whether information emanating from the media space is true or false.

With media audiences getting information from different media sources at the same time, their preferences of one media form over the other is an indication of their trust in that media outlet. Radio, television, and online portals stand out as platforms that media audiences give credibility for information emanating from such sources. While radio and television are trusted for the information they share, online portals are used by media audiences as a quasi-factchecking tool.

\section{REFERENCES}

Allcott, H., Gentzkow, M. \& Yu, C (2018). Trends in the Diffusion of Misinformation on Social Media. Retrieved From https://web.stanford.edu/ gentzkow/research/fakenews-trends.pdf?mod=article_inline

Amegatcher, K. A. (2014). Social Media in Ghana's Legacy Media Industry:

Collecting "Likes" Or Building a New Revenue Source? Dissertation submitted to the

Department of Business Administration, Ashesi University College In partial fulfilment of the requirements for the award of Bachelor of Science degree in Management Information Systems. Retrieved from https://air.ashesi.edu.gh/bitstream/handle/20.500.11988/57/anna.amegatcherAmegatcher\%20Anna\%20-\%20Thesis_397.pdf?sequence=1\&isAllowed=y

Charles Purcell, C. (2017). The Onion: inside the biggest 'fake news' outlet in the world. The Sunday morning herald. Retrieved from https://www.smh.com.au/entertainment/ the-onion-inside-the-biggest-fake-news-outlet-in-the-world-20170822-gy 1 chg.html Farkas, J \& Jannick Schou, J (2018). Fake News as a Floating Signifier:

Hegemony, Antagonism and the Politics of Falsehood, Javnost - The Public, 25(3), 
298-314. Retrieved from file:///C:/Users/NII/Desktop/fake\%20news/Farkas-and-Schou2018.pdf

Floridi, L. (2016). Fake News and a 400-year-old problem: We need to resolve the "posttruth" crisis." The Guardian, November 29. Retrieved from https://www. theguardian.com/technology/2016/nov/29/fake-news-echo-chamber-ethics-infosphereinternet-digital.

Gibbs, A. (1997). Focus groups. Social Research Update, 19. Retrieved from http://sru.soc.surrey.ac.uk/SRU19.html

Karikari, A. (1994). Proceedings of the National Conference on the Promotion and Privatization of Radio and Television Broadcasting in Ghana Held at GIMPA, Greenhill, Achimota, March 1-3, 1993. Ghana Universities Press.

Krueger, R. A. (2002). Designing and Conducting Focus Group Interviews.

Mare, A. \& Mabweazara W.H \& Dumusani Moyo, D. (2019). "Fake News" and CyberPropaganda in Sub-Saharan Africa: Recentering the Research Agenda, African Journalism Studies, 40(4), 1-12. Retrieved from file:///C:/Users/NII/Desktop/fake\%20news/Fake\%20News\%20and\%20Cyber\%20 Propaganda $\% 20$ in $\% 20$ Sub $\% 20$ Saharan $\% 20$ Africa $\% 20$ Recentering\%20the\%20Researc h\%20Agenda.pdf

Masadeh, A. M. (2012). Focus Group: Reviews and Practices. International Journal of Applied Science and Technology Vol. 2 (10). Retrieved From http://www.ijastnet.com/journals/Vol_2_No_10_December_2012/9.pdf

Methods American Statistical Association. (1997). Survey Research Methods. American Statistical Association, 1429 Duke Streett Alexandria, VA. Retrieved from http://www.prm.nau.edu/prm447/asa\%20brochures/focusgroups.pdf

Nelson, L. \& Taneja, H. (2018). The small, disloyal fake news audience: The role of audience availability in fake news consumption. Retrieved from https://journals.sagepub.com/doi/abs/10.1177/1461444818758715? journalCode $=$ n msa

Nielsen, K. R \& Graves L. (2017). News you don't believe": Audience perspectives on fake news. Fact sheet of Reuter Institute and University of Oxford. Retrieved from https://reutersinstitute.politics.ox.ac.uk/sites/default/files/201710/Nielsen\%26Graves_factsheet_1710v3_FINAL_download.pdf

Nili, A., Tate, M., \& Johnstone, D. (2017) "A Framework and Approach for Analysis of Focus Group Data in Information Systems Research," Communications of the Association for Information Systems: Vol. 40(1). Retrieved from https://core.ac.uk/download/pdf/193262384.pdf

Ognyanova, K., Lazer, D., Robertson, R. E., \& Wilson, C. (2020). Misinformation in action: Fake news exposure is linked to lower trust in media, higher trust in government when your side is in power. The Harvard Kennedy School (HKS) Misinformation Review, Volume 1(4)

Pollard, M. \& Kavanagh, J. (2019). Profiles of News Consumption, Platform Choices, Perceptions of Reliability and Partisanship. Published by the RAND Corporation, Santa Monica, Calif. Retrieved from https://www.rand.org/pubs/research_reports/RR4212.html

Posetti, J \& Matthews, A. (2018). A short guide to the history of 'fake news' and disinformation. International Centre for Journalists. 
Quarshie, O. H \& Ami-Narh, J. (2012). The Growth and Usage of Internet in Ghana. Journal of Emerging Trends in Computing and Information Sciences, Vol 3 (9). Retrieved from https://www.researchgate.net/publication/ 280562028_The_Growth_and_Usage_of_Internet_in_Ghana

Scheufelea A. D \& Krausea M. N (2019), Science audiences, misinformation, and fake news. Paper presented at the Arthur M. Sackler Colloquium of the National Academy of Sciences, Washington, DC. Retrieved from https://www.pnas.org/content/pnas/116/16/7662.full.pdf

Shu, K, Sliva, A, Wang, S, Tang, J, \& Liu, H. (2018). Fake News Detection on Social Media: A Data Mining Perspective. SIGKDD Explorations, 19(1). Retrieved from http://users.wpi.edu/ kmus/ECE579M_files/ReadingMaterials/fake_news[1828].p df

Sikanku, G. E. (2008). Inter-media agenda-setting effects in Ghana: newspaper vs. online and state vs. private. A thesis submitted to the graduate faculty in partial fulfilment of the requirements for the degree of Master Of Science Major: Journalism and Mass Communication. Iowa State University Ames, Iowa.

Victoria Nana Ama Figyina Adu, F. A. N. V. (2003). Issues of Credibility in Radio News: Sunyani Residents' Perception of Sky FM and Radio Bar News. Thesis Submitted to the University Of Ghana, Legon. Retrieved from http://ugspace.ug.edu.gh/bitstream/handle/123456789/34227/Issues\%20Of\%20Cr edibility $\% 20$ In $\% 20$ Radio $\% 20$ News $\% 20$ Sunyani $\% 20$ Residents $\% 27 \% 20$ Perception $\% 20$ Of $\% 20$ Sky $\% 20$ FM $\% 20$ And $\% 20$ Radio $\% 20$ Bar $\% 20$ News $\% 20$ Bulletins.pdf? sequence $=1$ \&isAllowed=y 